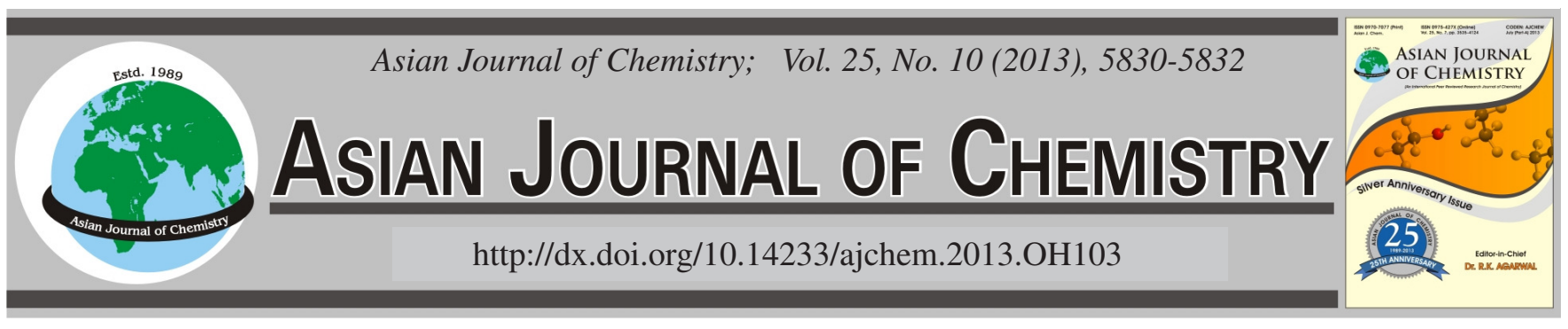

\title{
Morphological Influence of Molybdenum Disulfide Nanoparticles on Powder Lubrication and Photocatalysis $\dagger$
}

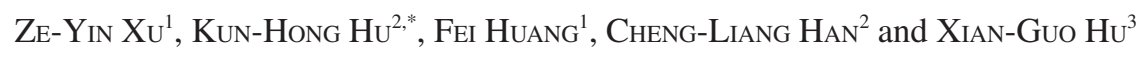

${ }^{1}$ Department of Mechanical Engineering, Hefei University, Hefei 230601, P.R. China

${ }^{2}$ Department of Chemical and Materials Engineering, Hefei University, Hefei 230601, P.R. China

${ }^{3}$ Institute of Tribology, Hefei University of Technology, Hefei 230009, P.R. China

*Corresponding author: Email: hukunhong@gmail.com

AJC-13346

The lubricating and catalytic properties of two kinds of nano- $\mathrm{MoS}_{2}$, namely nano-sphere and nano-platelet, were investigated. Results
showed that the amount of nano-spheres with a low $\mathrm{BET}$ area in the contact area was not enough to lubricate the steel friction pair.
However, $\mathrm{MoS}_{2}$ nano-platelets with a high $\mathrm{BET}$ area could well function as a powder lubricant. The high BET area also improved the
catalytic activity of $\mathrm{MoS}_{2}$ nano-platelets. The findings indicated $\mathrm{MoS}_{2}$ nano-platelets have potential applications in powder lubrication
and photocatalysis.
Key Words: Molybdenum disulfide, Nanoparticles, Tribology, Lubrication, Photocatalysis.

\section{INTRODUCTION}

The shape remarkably affects the properties of nano- $\mathrm{MoS}_{2}{ }^{1}$. Spherical nano- $\mathrm{MoS}_{2}\left(\mathrm{MoS}_{2}\right.$ nano-sphere) usually reveals better tribological properties than platelet-like nano- $\mathrm{MoS}_{2}\left(\mathrm{MoS}_{2}\right.$ nano-platelet $)^{2}$ because of its particular lubricating mechanisms ${ }^{3,4}$. However, the nano-platelet has higher catalytic activity than the nano-sphere. The catalytic mechanism of $\mathrm{MoS}_{2}$ can be explained by the 'rim-edge site' model ${ }^{5}$.

Though literatures reported the lubricating advantages of spherical nano- $\mathrm{MoS}_{2}$ over platelet-like nano- $\mathrm{MoS}_{2}{ }^{1,2}$, the results in this work showed that $\mathrm{MoS}_{2}$ nano-spheres could not work in a powder-lubrication manner. Moreover, the nano-spheres also represent lower catalytic activity than the nano-platelets.

\section{EXPERIMENTAL}

Two nano- $\mathrm{MoS}_{2}$ samples in different shape were synthesized using chemical methods reported by $\mathrm{Hu}$ and $\mathrm{Hu}^{6}$. The characterization of nano- $\mathrm{MoS}_{2}$ was done on a Hitachi model H-800 transmission electron microscopy (TEM), a JEOL model JEM-2010 high-resolution transmission electron microscopy (HRTEM) and a micromeritics model ASAP $2020 \mathrm{M}+\mathrm{C}$ physical and chemical adsorption analyzer.

Tribological tests: The tribological tests were completed on an MQ-800 end-face tribometer with an ASTM 1045 steel friction pair in a powder-lubrication manner of $\mathrm{MoS}_{2}$ at 1.6
$\mathrm{MPa}$ and $0.4 \mathrm{~m} / \mathrm{s}$. Fig. 1 shows the schematic of the end-face powder-lubrication manner.

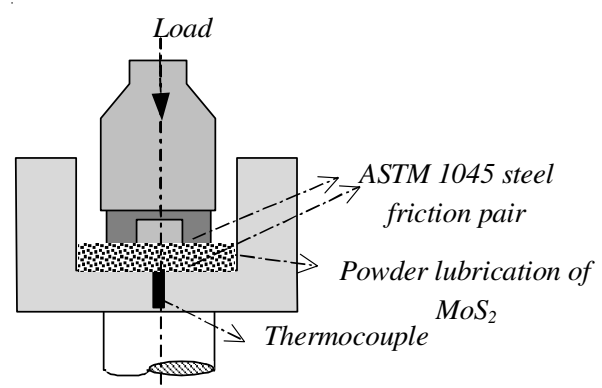

Fig. 1. Schematic diagram of the end-face tribological test

Catalytic tests: The catalytic properties were investigated using the degradation reaction of malachite green. The conversion rate (\%) was evaluated by the absorbance (A) of malachite green solution that was measured on a 721 spectrophotometer.

\section{RESULTS AND DISCUSSION}

Characterization of nano-MoS $\mathbf{S}_{2}$ Fig. 2 provides micrographs of the two kinds of $\mathrm{MoS}_{2}$ nanoparticles. As shown in Fig. 2a, nano- $\mathrm{MoS}_{2}$ is in a hollow sphere-like shape with diameters of 100-200 nm and shells of about $15 \mathrm{~nm}$. The other 
nano- $\mathrm{MoS}_{2}$ in Fig. $2 \mathrm{~b}$ comprises a platelet-like structure with thickness of about $8 \mathrm{~nm}$ and lengths of 20-40 nm.
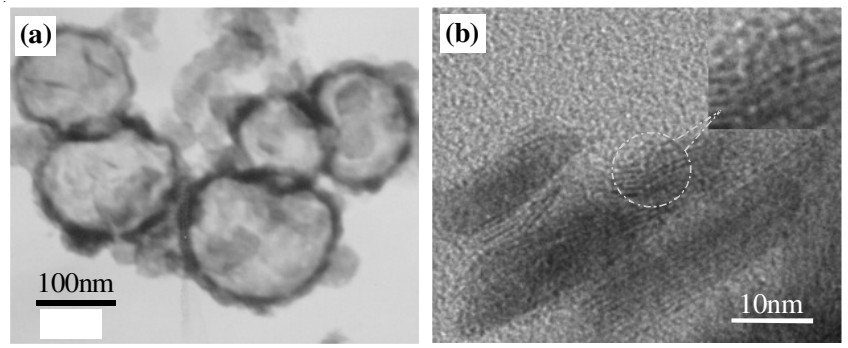

Fig. 2. Micrographs of (a) nano-spheres and (b) nano-platelets

Tribological properties of nano-MoS $\mathrm{M}_{2}$ : The friction coefficients lubricated by nano-platelets at $0.4 \mathrm{~m} / \mathrm{s}$ and $1.6 \mathrm{MPa}$ were remarkably lower than these by nano-spheres (Fig. 3). The friction-time curve lubricated by nano-platelets was also more stable than that by nano-spheres. The friction temperature rapidly increased within $8 \mathrm{~min}$ to a very high value as lubricated by nano-spheres. Thus, the test was not completed. The result concerning nano-spheres is similar to that of a dry friction, indicating that the amount of nano-spheres in the contact area was not enough to lubricate the friction pair.
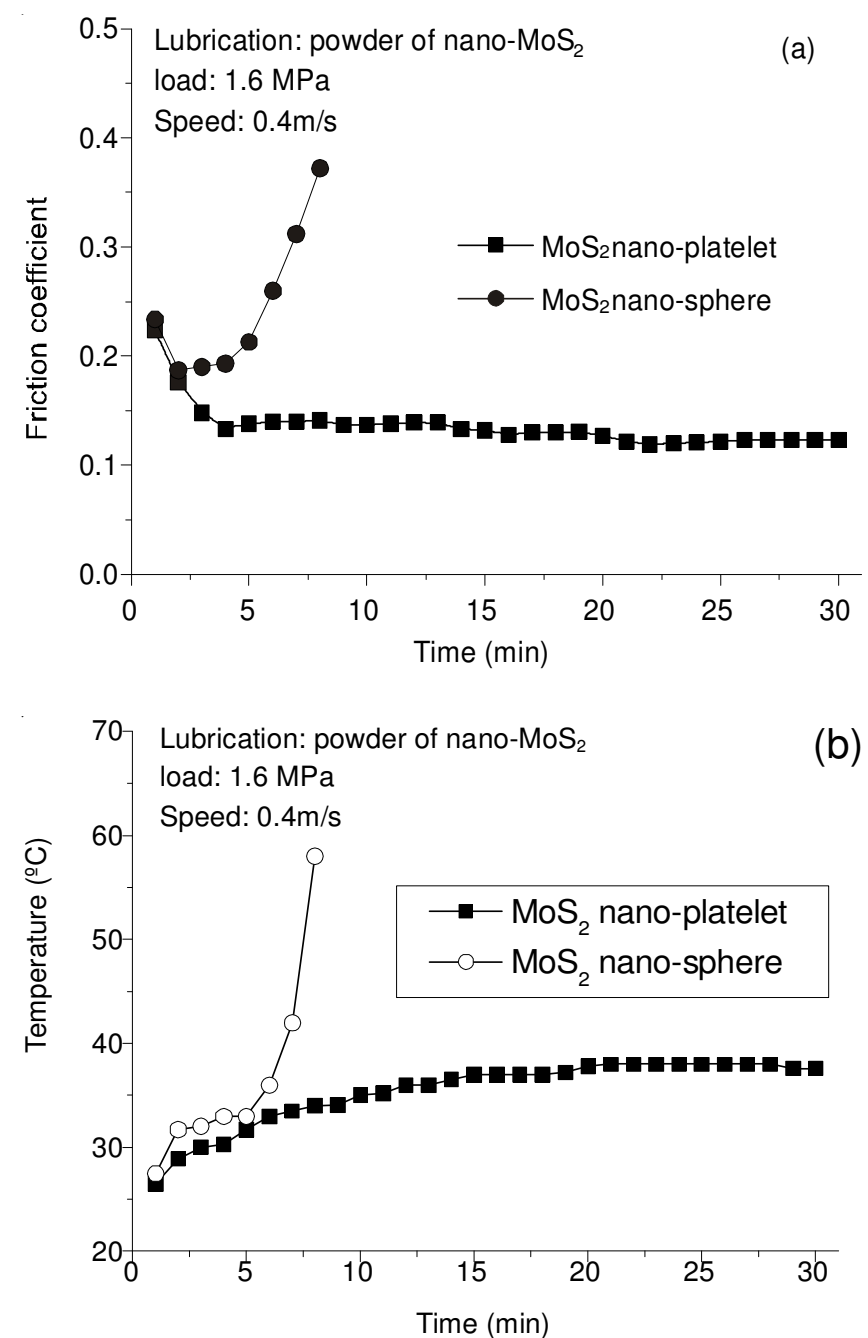

Fig. 3. Results of end-face tests: (a) friction coefficient and (b) friction temperature
However, previous researches found that spherical $\mathrm{MoS}_{2}$ nanoparticles usually have lubricating advantages over plateletlike $\mathrm{MoS}_{2}$ because of the particular lubricating mechanisms of spherical structures ${ }^{3,4}$. The bad performance of nano-spheres in powder lubrication does not negate the lubricating advantages of spherical structures. This is because the amount of nano-spheres with a low BET area in the contact area was not enough to lubricate the friction pair.

Catalytic properties of nano- $\mathrm{MoS}_{2}$ : Two kinds of nano$\mathrm{MoS}_{2}$ represented good activity for the degradation of malachite green at $20^{\circ} \mathrm{C}$ (Fig. 4a). As compared with nano-sphere, nano-platelet revealed higher catalytic activity. The catalytic activity of nano- $\mathrm{MoS}_{2}$ was weakened as repeatedly used for 4 cycles (Fig. 4b). However, the weakening of activity was not very remarkable, indicating nano- $\mathrm{MoS}_{2}$ catalysts have a good regeneration performance.
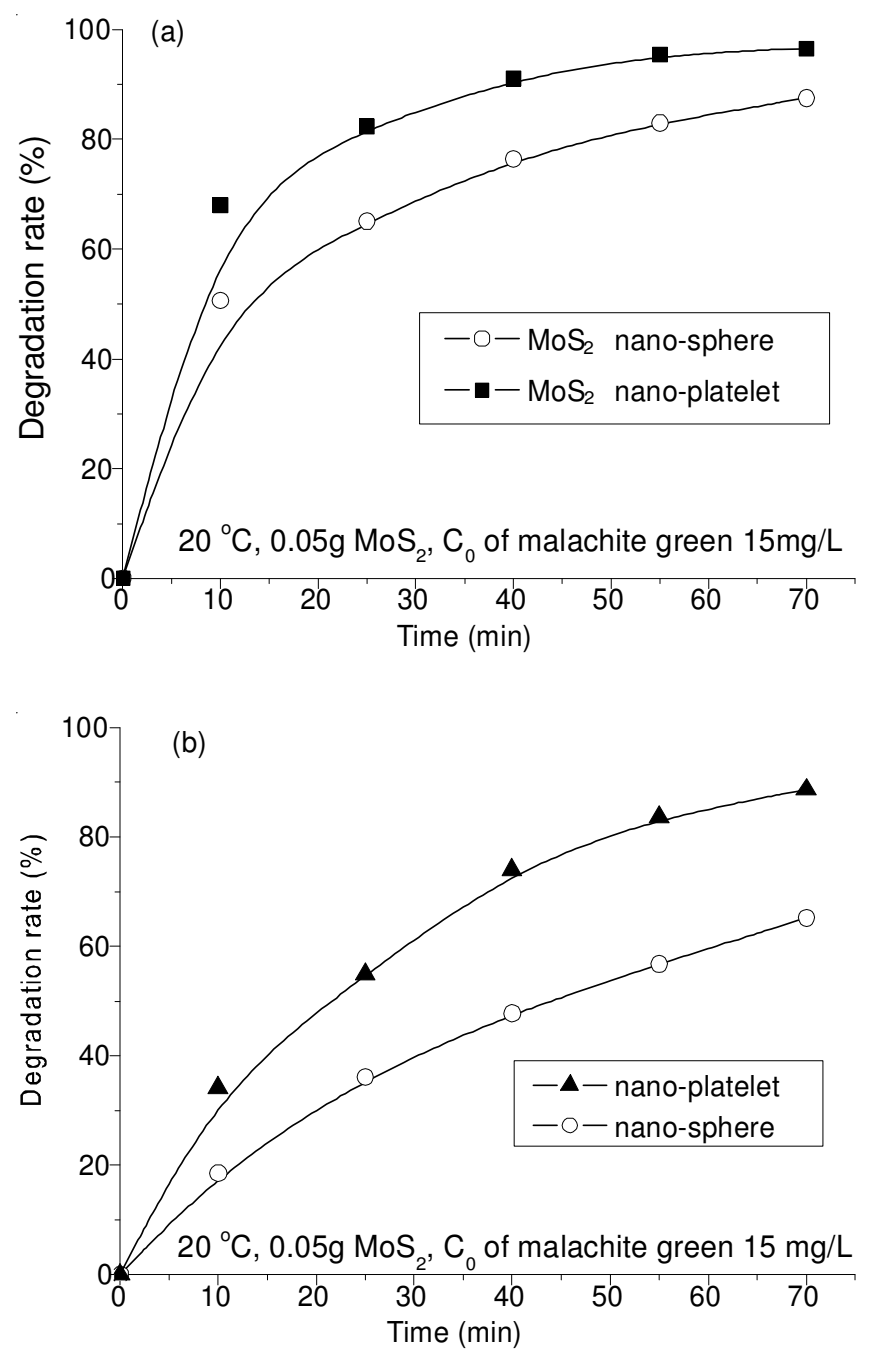

Fig. 4. Catalytic activity of $0.1 \mathrm{~g} \mathrm{MoS}_{2}$ used for (a) the $1^{\text {st }}$ cycle and (b) the $4^{\text {th }}$ cycle

$\mathrm{MoS}_{2}$ contains three kinds of surface (or site), i.e. basal surface, rim site and edge site ${ }^{5}$. The catalytic active sites are located at the rim-edge surface. $\mathrm{MoS}_{2}$ nano-platelet provided the active rim-edge surface and showed high activity for the degradation of malachite green. However, nano-sphere can only offered basal surfaces. Thus, it should reveal a low activity 
in the degradation reaction. However, the activity of basal surfaces on nano-spheres was improved by the incurvation of $\mathrm{MoS}_{2}$ layers ${ }^{7}$. Thus, nano-spheres still represented good activity in the degradation reaction.

Adsorption behaviour of nano- $\mathrm{MoS}_{2}$ : Results given in Figs. 5 and 6 indicate the two kinds of nano- $\mathrm{MoS}_{2}$ have a similar adsorption behaviour. However, the adsorbed quantity on nanoplatelets is remarkably higher than on nano-sphere. The two liner correlation coefficients exceed 0.9999, indicating the BET results are reasonable. The nano-platelets have a BET area of $42 \mathrm{~m}^{2} / \mathrm{g}$, whereas the BET area of nano-spheres is only at 19 $\mathrm{m}^{2} / \mathrm{g}$. The low surface area decreased the adsorption of nanosphere on the friction surface. The amount of nano-spheres in the contact area was not enough to lubricate the friction pairs. The relatively high surface area of nano-platelets increased the adsorption on the friction surfaces, leading to a stable lubrication and also offered more active sites for the degradation of malachite green.
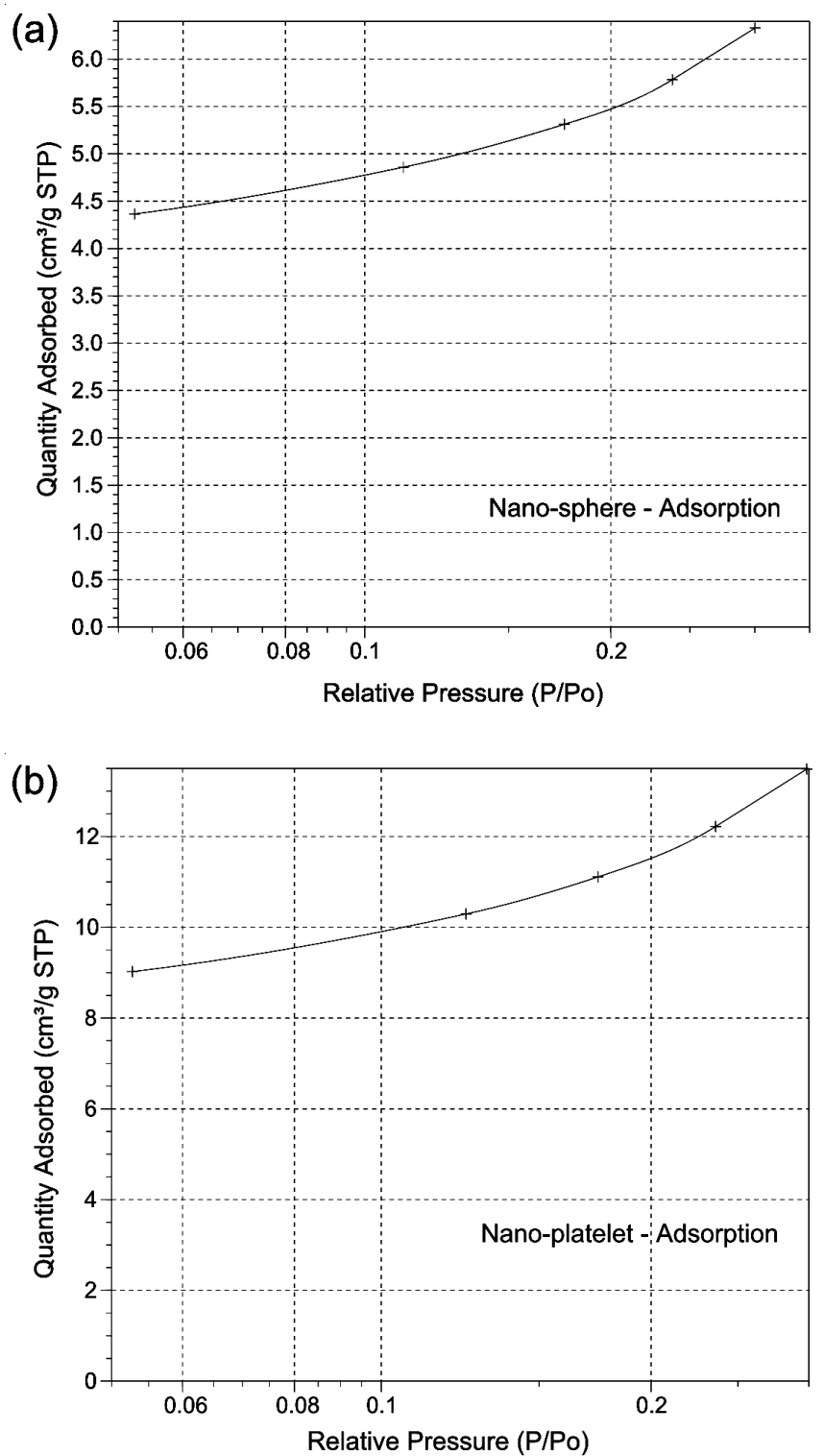

Fig. 5. Adsorption isotherm plot of $\mathrm{MoS}_{2}$ : (a) nano-spheres and (b) nanoplatelets
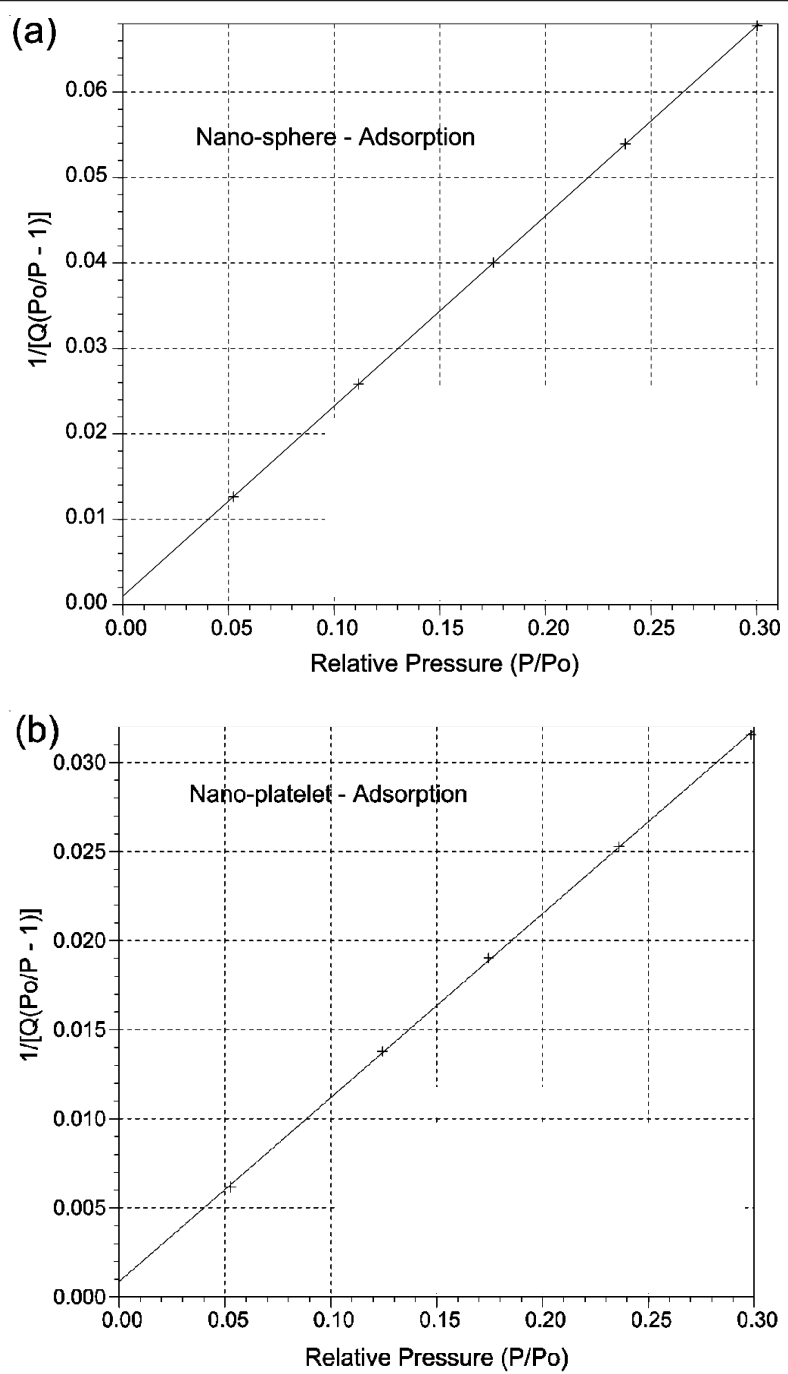

Fig. 6. BET surface area plot of $\mathrm{MoS}_{2}$ : (a) nano-spheres and (b) nano-platelets

\section{Conclusion}

$\mathrm{MoS}_{2}$ nano-spheres cannot work in the powder-lubrication manner, whereas $\mathrm{MoS}_{2}$ nano-platelets represent a stable lubricating performance. As compared to $\mathrm{MoS}_{2}$ nano-spheres, $\mathrm{MoS}_{2}$ nano-platelets have better catalytic activity for the degradation of malachite green.

\section{ACKNOWLEDGEMENTS}

This work was supported by the National Natural Science Foundation of China (grant no. 50905054 and 51275143) and the China Postdoctoral Science Foundation funded project (Grant No. 2011M500110).

\section{REFERENCES}

1. J.V. Lauritsen, J. Kibsgaard, S. Helveg, H. Topsøe, B.S. Clausen, E. Lægsgaard and F. Besenbacher, Nat. Nanotechnol., 2, 53 (2007).

2. K.H. Hu, X.G. Hu and X.J. Sun, Appl. Surf. Sci., 256, 2517 (2010).

3. J. Tannous, F. Dassenoy, I. Lahouij, T. Le Mogne, B. Vacher, A. Bruhács and W. Tremel, Tribol. Lett., 41, 55 (2011).

4. I. Lahouij, F. Dassenoy, B. Vacher and J.M. Martin, Tribol. Lett., 45, 131 (2012).

5. M. Daage and R.R. Chianelli, J. Catal., 149, 414 (1994).

6. K.H. Hu and X.G. Hu, Mater. Sci. Technol., 25, 407 (2009).

7. K.H. Hu, X.G. Hu, Y.F. Xu and X.Z. Pan, React. Kinet. Mech. Catal., 100, 153 (2010). 